\title{
Removal of Zinc from Aqueous Solutions by Magnetite Silica Core-Shell Nanoparticles
}

\author{
Masoomeh Emadi, Esmaeil Shams, and Mohammad Kazem Amini \\ Chemistry Department, University of Isfahan, Isfahan 81746-73441, Iran \\ Correspondence should be addressed to Esmaeil Shams; e_shams@chem.ui.ac.ir
}

Received 8 March 2012; Revised 1 June 2012; Accepted 1 June 2012

Academic Editor: Nurettin Sahiner

Copyright (C) 2013 Masoomeh Emadi et al. This is an open access article distributed under the Creative Commons Attribution License, which permits unrestricted use, distribution, and reproduction in any medium, provided the original work is properly cited.

\begin{abstract}
Magnetite silica core-shell nanoparticles $\left(\mathrm{Fe}_{3} \mathrm{O}_{4}-\mathrm{SiO}_{2}\right)$ were synthesized and evaluated as a nanoadsorbent for removing $\mathrm{Zn}$ (II) from aqueous solutions. The core-shell nanoparticles were prepared by combining coprecipitation and sol-gel methods. Nanoparticles were characterized by X-ray diffraction, transmission electron microscopy (TEM), and FT-IR. The magnetization values of nanoparticles were measured with vibrating sample magnetometer (VSM). The adsorption of $\mathrm{Zn}$ (II) ions was examined by batch equilibrium technique. The effects of $\mathrm{pH}$, initial $\mathrm{Zn}$ (II) concentration, and contact time on the efficiency of $\mathrm{Zn}$ (II) removal were studied. The equilibrium data, analyzed by using Langmuir and Freundlich isotherm models, showed better agreement with the former model. Using the Langmuir isotherm model, maximum capacity of the nanoadsorbent for $\mathrm{Zn}$ (II) was found to be $119 \mathrm{mg} \mathrm{g}^{-1}$ at room temperature. Kinetic studies were conducted and the resulting data were analyzed using first- and second-order equations; pseudo-second-order kinetic equation was found to provide the best correlation. The adsorption and sedimentation times were very low. The nanoadsorbent can be easily separated from aqueous solution by a magnet. Repeated adsorption acid regeneration cycles were performed to examine the stability and reusability of the nanoadsorbent. The result of this study proved high stability and reusability of $\mathrm{Fe}_{3} \mathrm{O}_{4}-\mathrm{SiO}_{2}$ as an adsorbent for $\mathrm{Zn}$ (II) ions.
\end{abstract}

\section{Introduction}

Water pollution due to toxic heavy metals remains a serious environmental and public problem [1]. Among heavy metals, zinc is frequently used in the production of steel, alkaline batteries, and anticorrosive paintings. High concentrations of $\mathrm{Zn}$ (II) have been observed in wastewaters from pharmaceutical, galvanizing, paint, pigment, insecticide, and cosmetic industries. It has also been reported that zinc ion occurs in the leachate of landfills at high concentrations $[2,3]$. Low concentration of zinc is necessary for the growth of living systems, but it can easily form large aggregates, which may become harmful to health once beyond the permissible limits [3]. Thus, the removal of zinc like other heavy metals from aqueous solutions is a critical challenge for environmental researchers.
Various processes and methods such as precipitation, electrochemical treatment, chemical oxidation reduction, membrane separation, solvent extraction, and ion exchange have been employed to remove metal pollutants from aqueous solutions [4]. However, most of these methods suffer from low removal efficiency, especially when large volumes of dilute heavy metal solutions are present [5]. Adsorption is one of the most effective and economic techniques for removing heavy metal ions from aqueous solutions. The efficiency of adsorption relies on the capability of the adsorbent to concentrate or adsorb metal ions from solution onto its surfaces and the rate of removing ions from the solution. Different adsorbents such as activated carbon [6], zeolites [7, $8]$, resins $[9,10]$, biosorbents $[4,11]$, hydrogel, and magnetic hydrogel $[12,13]$ have been used for the removal of heavy metal ions by adsorption. Despite the availability of a number 
of adsorbents for the removal of low concentrations of heavy metal ions from aqueous solutions, there is still a need for the development of new adsorbent with superior adsorption capacity, facile adsorption-desorption kinetics, high stability, and easiness of operation.

Recently, nanometer-sized materials have been used for wastewater treatment [14-16]. These materials possess a series of unique physical and chemical properties. These materials have large surface area and are easily dispersed in aqueous solutions. In addition, a large number of their atoms are surface atoms which are unsaturated and have high adsorption capacities to many metal ions $[15,17]$. However, from a practical point of view, there is a major drawback to the application of such nanomaterials for treating wastewater. Because the treatment of wastewater is usually conducted in a suspension of the nanostructures, an additional separation step is required to remove the nanomaterials from a large volume of solution, resulting in increased expenses [18].

Nanometer-sized iron oxide-based materials with superparamagnetic characteristic are very effective as adsorbents for heavy metal ions removal. Superparamagnetic particles adhered to the target can be removed very quickly from a matrix using a magnetic field, but they do not retain their magnetic properties when the field is removed [19]. This system also has several advantages compared with conventional and other nanoadsorbents in that the process does not generate secondary waste and the materials involved can be recycled and facilely used on an industrial scale. Furthermore, the magnetic particles can be tailored to fix and separate metal species in water, wastes, or slurries [20, 21]. In recent years, different magnetic nanoparticles (MNPs) have been synthesized and used as sorbents for removal or preconcentration of heavy metal ions [14, 22-28]. Unmodified magnetic $\mathrm{Fe}_{2} \mathrm{O}_{3}$ and $\mathrm{Cu}(\mathrm{II})$ ion imprinted $\mathrm{Fe}_{3} \mathrm{O}_{4}$ nanoparticles were employed as adsorbents for the removal of $\mathrm{Cr}(\mathrm{VI})$ [22] and $\mathrm{Cu}(\mathrm{II})$ [23], respectively, from wastewater. Capturing of $\mathrm{As}(\mathrm{III})$ and $\mathrm{As}(\mathrm{VI})$ by magnetite $\left(\mathrm{Fe}_{3} \mathrm{O}_{4}\right)$ nanoparticles modified with oleic acid have been reported [24]. Undecanoic acid-modified $\mathrm{Fe}_{3} \mathrm{O}_{4}$ nanoparticles have been reported to be efficient for removal of $\mathrm{Cd}(\mathrm{II})$ [25]. Attachment of chitosan [26], humic acid [27], $\alpha$-ketoglutaric acid-modified chitosan [14], and dimercaptosuccinic acid [19] on $\mathrm{Fe}_{3} \mathrm{O}_{4}$ nanoparticles resulted in magnetic sorbent materials effective for the removal of heavy metal ions from water. However, it should be pointed out that uncoated magnetic nanoparticles are highly susceptible to oxidation when exposed to atmosphere and also susceptible to leaching under acidic conditions $[23,29]$. In addition, due to the hydrophobic interactions between the sub-nm size particles, iron oxide MNPs tend to aggregate to micron size clusters. In the presence of an external magnetic field, further magnetization of these aggregates can occur increasing their aggregation [29]. The aggregation of MNPs may alter their magnetic properties and their adsorption efficiency. Therefore, stabilization of iron oxide MNPs by coating their surface is an important issue. Organic polymers, silica, metals (e.g., gold), and organic dyes have been used as stabilizing agents for iron oxide MNPs [29]. Silica coating has attractive properties including: biocompatibility [29], high adsorption capacity, acid-base properties, insolubility in most solvents, and chemical and thermal stability [30]. Being hydrophilic in nature, silica-coated core-shell MNPs can be easily dispersed in aqueous solutions. Furthermore, since $\mathrm{SiO}_{2}$ is stable under acidic conditions, iron oxide- $\mathrm{SiO}_{2}$ MNPs can be used as adsorbent in acidic solutions. The surface of silica is dominated by hydroxyl or silanol groups. Silanol groups participate in adsorption as well as chemical modification of the silica surface. At pHs greater than its isoelectric point $(>2)$ silica exhibits ion exchange capabilities via these weakly acidic silanol groups [31]. In addition, silica can be grafted with a variety of functional groups, leading to considerable enhancement of their surface properties. In spite of their good characteristics, the use of silica-coated core-shell MNPs in heavy metal removal is quite rare $[32,33]$.

The versatile application of several types of silica as adsorbent for heavy metal ions removal [34, 35] motivated us to synthesize $\mathrm{Fe}_{3} \mathrm{O}_{4}-\mathrm{SiO}_{2}$ for this purpose. Magnetite nanoparticles were synthesized by coprecipitation method and their surface covered with silica shell using sol-gel technique in alkaline solution. The nanoparticles were characterized and tested as adsorbent for $\mathrm{Zn}$ (II) removal from aqueous solutions. The important factors affecting the adsorption efficiency such as solution $\mathrm{pH}$, contact time, and initial $\mathrm{Zn}$ (II) concentration were investigated. The best kinetic and isotherm models were found from experimental data.

\section{Materials and Methods}

2.1. Synthesis of $\mathrm{Fe}_{3} \mathrm{O}_{4}-\mathrm{SiO}_{2}$ Nanoparticles. Chemical coprecipitation as a simple but effective method for preparation of hydrophilic nanoparticles [36] was used for the preparation of magnetite nanoparticles by a little modification of the methodology already described in the literature [37]. According to this method, $3.5 \mathrm{~g} \mathrm{FeCl}_{2} \cdot 4 \mathrm{H}_{2} \mathrm{O}$ and $8.0 \mathrm{~g} \mathrm{FeCl}_{3} \cdot 6 \mathrm{H}_{2} \mathrm{O}$ with molar ratio $1: 2$ were dissolved in $38 \mathrm{~mL}$ of deoxygenated $0.4 \mathrm{M} \mathrm{HCl}$ solution. The resulting solution was rapidly added to $375 \mathrm{~mL}$ of deoxygenated $0.7 \mathrm{M}$ ammonia solution under argon flow. After sonication for 30 minutes, the magnetite nanoparticles were separated with a permanent magnet and washed twice with pure ethanol. The synthesized MNPs were suspended in $150 \mathrm{~mL}$ deionized water for use in the next steps.

Classical Stöber method [38] (base-catalyzed hydrolysis and condensation of tetraethoxysilane (TEOS)) was used for coating magnetite nanoparticles with a silica shell. Typically, $20 \mathrm{~mL}$ of magnetite suspended in water was added to $200 \mathrm{~mL}$ 2-propanol and sonicated at room temperature for $15 \mathrm{~min}$ under argon flow. Then $20 \mathrm{~mL}$ water and $10 \mathrm{~mL} \mathrm{NH}_{3}(28 \%$, Merck) were added, respectively, and after $15 \mathrm{~min} 1.3 \mathrm{~mL}$ of TEOS (99\%, Aldrich) was introduced into the suspension and the mixture was again sonicated for $1 \mathrm{~h} . \mathrm{Fe}_{3} \mathrm{O}_{4}-\mathrm{SiO}_{2}$ nanoparticles was centrifuged at $3000 \mathrm{rpm}$ for 10 minutes, the solvent was discarded and nanoparticles were washed two times with water and ethanol, respectively, and dried in vacuum oven at room temperature.

2.2. Characterization of $\mathrm{Fe}_{3} \mathrm{O}_{4}-\mathrm{SiO}_{2}$. The synthesized MNPs were characterized using X-ray diffraction (XRD) (Bruker 
D8 Advance, with Ni-filtered $\mathrm{Cu}-\mathrm{K}_{\alpha}$ source of $1.5406 \AA$ ), transmission electron microscopy (TEM) (Phillips-CM10 operating at $100 \mathrm{kV}$ with a Cu grid), and FT-IR (Jasco model 6300). Vibrating sample magnetometer (VSM) (PAR EG\&G 4500) was used to determine magnetization value of the MNPs. EDX spectra were recorded by Energy-dispersive Xray spectroscopy (EDX) (Philips XL 30).

2.3. Batch Removal Experiments. Adsorption of $\mathrm{Zn}$ (II) was carried out by batch technique at room temperature. The isotherm studies were performed by mixing $10 \mathrm{mg}$ adsorbent (dry) with $10 \mathrm{~mL}$ of a solution containing $\mathrm{Zn}\left(\mathrm{NO}_{3}\right)_{2}$ at known concentration into a $20 \mathrm{~mL}$ polypropylene tube and insert it in the ultrasonic bath. After reaching adsorption equilibrium, MNPs were separated from the aqueous solution using a $1.2 \mathrm{~T}$ neodymium iron boron magnet. Then metal analysis of the solutions was performed by atomic absorption spectrophotometry (AAS) (Shimadzu AA-670). The equilibrium concentration of the adsorbed $\mathrm{Zn}(\mathrm{II}), q_{e}$ (in $\mathrm{mgg}^{-1}$ ), was calculated according to (1):

$$
q_{e}=\frac{\left(C_{o}-C_{e}\right) V}{M}
$$

where $C_{o}$ and $C_{e}$ (in $\mathrm{mg} \mathrm{L}^{-1}$ ) are the initial and equilibrium concentrations of $\mathrm{Zn}(\mathrm{II})$ in solution, respectively, $V$ (in $\mathrm{L}$ ) is the total volume of the solution, and $M$ (in g) is the adsorbent mass.

The effect of $\mathrm{pH}$ on the adsorption of $\mathrm{Zn}$ (II) by the MNPs was studied in the range of 2.0-8.0. The $\mathrm{pH}$ was adjusted by adding appropriate amounts of $0.1 \mathrm{M}$ hydrochloric acid or $0.1 \mathrm{M}$ sodium hydroxide.

Kinetic studies were performed under similar conditions used for isotherm studies and at $\mathrm{pH} 6.0$ which was the optimum $\mathrm{pH}$ for $\mathrm{Zn}(\mathrm{II})$ removal. In these studies aliquots of the supernatant were withdrawn for $\mathrm{Zn}$ (II) analysis at different periods of time.

2.4. Desorption, Reusability, and Stability Studies. To study the regeneration efficiency of the adsorbent, the adsorption step was performed batchwise as described previously, and then nanoadsorbents were separated magnetically and added to $1.0 \mathrm{~mL}$ of the desorbing solution. The mixture was placed in ultrasonic bath for $15 \mathrm{~min}$ at room temperature. To evaluate desorption efficiency, MNPs were separated magnetically and the concentration of $\mathrm{Zn}$ (II) in the desorbing solution was determined using AAS. The reusability of the adsorbent was studied by repeating the adsorption-desorption cycles consecutively.

Stability of $\mathrm{Fe}_{3} \mathrm{O}_{4}-\mathrm{SiO}_{2}$ nanoparticles under harsh acidic conditions was examined by dispersing $20 \mathrm{mg}$ of the nanoparticles in $10.0 \mathrm{~mL} 2.0 \mathrm{M} \mathrm{HCl}$ and stirring for $12 \mathrm{~h}$. The iron concentration in leachate was measured by AAS.

\section{Results and Discussion}

3.1. Nanoadsorbent Characterization. Powder X-ray diffraction (XRD) patterns were used to identify the crystalline

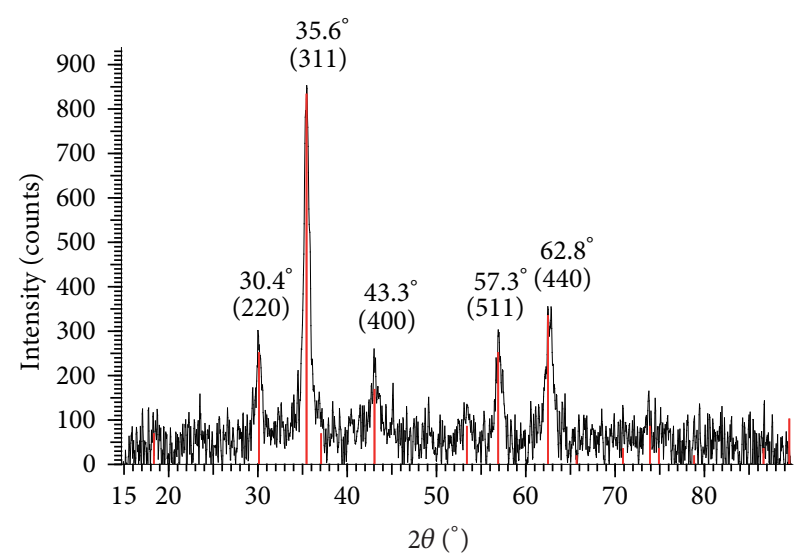

(a)

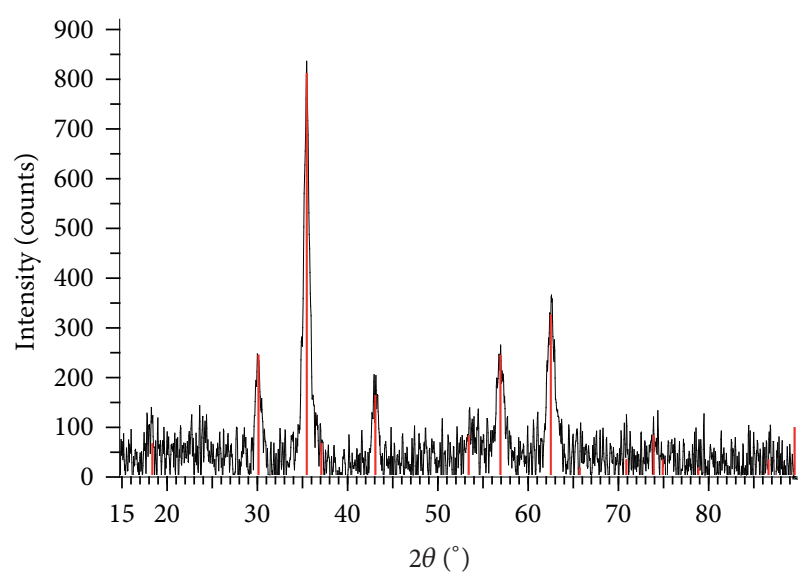

(b)

Figure 1: X-ray patterns of (a) $\mathrm{Fe}_{3} \mathrm{O}_{4}$ and (b) $\mathrm{Fe}_{3} \mathrm{O}_{4}-\mathrm{SiO}_{2}$.

structure of magnetite and $\mathrm{Fe}_{3} \mathrm{O}_{4}-\mathrm{SiO}_{2}$. XRD peaks with $2 \theta$ at $30.4^{\circ}, 35.6^{\circ}, 43.3^{\circ}, 57.3^{\circ}$, and $62.8^{\circ}$ (Figure $1(\mathrm{a})$ ) show good consistency with the reported data and can be indexed to pure phase of $\mathrm{Fe}_{3} \mathrm{O}_{4}$ structure. The average crystallite size of the $\mathrm{Fe}_{3} \mathrm{O}_{4}$ nanoparticles calculated from Scherrer's equation was $11 \mathrm{~nm}$. Figure 1(b) shows that the XRD pattern of the $\mathrm{Fe}_{3} \mathrm{O}_{4}$ $\mathrm{SiO}_{2}$ nanoparticles is very similar to that of the uncoated $\mathrm{Fe}_{3} \mathrm{O}_{4}$ nanoparticles. This indicates the stability of the crystalline phase of $\mathrm{Fe}_{3} \mathrm{O}_{4}$ nanoparticles after silica coating. It also indicates that the silica coating is in amorphous form.

The background corrected FT-IR spectra of MNPs are presented in Figure 2. The absorption bands around 580-610 and $410-440 \mathrm{~cm}^{-1}$ in the IR spectra of both $\mathrm{Fe}_{3} \mathrm{O}_{4}$ and $\mathrm{Fe}_{3} \mathrm{O}_{4}-\mathrm{SiO}_{2}$ nanoparticles (Figures 2(a) and 2(b)) correspond to $\mathrm{Fe}-\mathrm{O}$ bonds, and are attributed to the formation of the ferrite phase. In addition, the final product obtained from the coprecipitation was dense, black and magnetic implying the presence of magnetite as the main phase. Comparison of the FT-IR patterns shows a pronounced change in the $1300-700 \mathrm{~cm}^{-1}$ region, indicating the presence of the silica coating. The peaks at 970 and $1088 \mathrm{~cm}^{-1}$ correspond to symmetric stretching of $\mathrm{Si}-\mathrm{O}$ and $\mathrm{Si}-\mathrm{O}-\mathrm{Si}$, respectively [39], and 


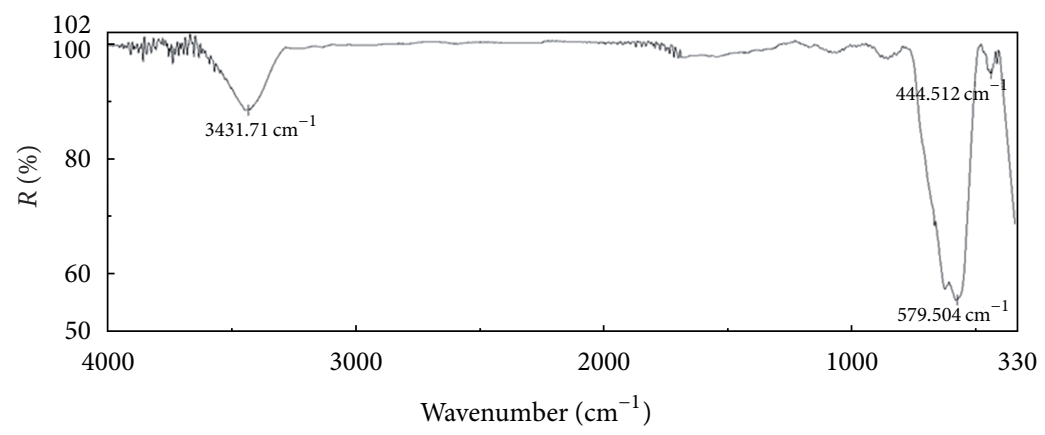

(a)

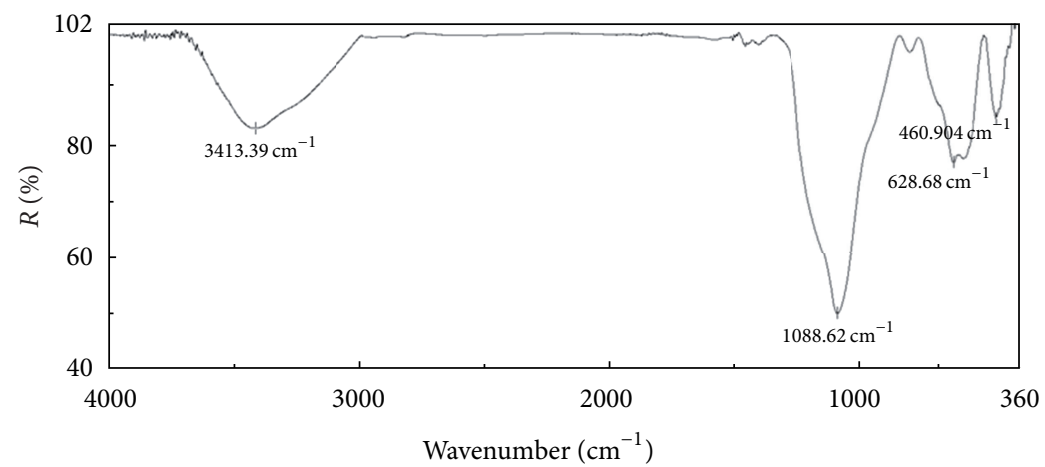

(b)

FIGURE 2: FT-IR of (a) uncoated and (b) silica-coated magnetite nanoparticles.

The broad band around $3400 \mathrm{~cm}^{-1}$ can be assigned to $\mathrm{O}-\mathrm{H}$ stretching vibrations.

Figure 3(a) shows the TEM image of the MNPs. The mean diameter determined from the TEM image is about $20 \mathrm{~nm}$, which agrees approximately with the value calculated from the Scherrer formula for the strongest diffraction peak in the X-ray diffraction patterns. As shown in the TEM image, despite their hydrophilicity, the magnetite particles tend to aggregate. This is due to the ultrasmall size and the requirement to decrease their interface energy [36]. Therefore, the crystallite size evaluated from X-ray diffraction is smaller than the nanoparticles size estimated from TEM. Silica phases can be seen in Figure 3(b) which shows the TEM image of $\mathrm{Fe}_{3} \mathrm{O}_{4}-\mathrm{SiO}_{2}$. The average size of nanoparticles in Figure 3(b) $(30 \mathrm{~nm})$ is larger than that of Figure 3(a) $(20 \mathrm{~nm})$ indicating that the silica shell thickness is in the nanometer range.

The EDX spectrum of silica-coated nanoparticles is shown in Figure 4. Atomic weight ratio of $\mathrm{O}: \mathrm{Si}: \mathrm{Fe}$ was $37.423: 27.086: 35.491$, which indicates the magnetite nanoparticles are successfully coated by silica.

Magnetic measurements of the pure and the silica coated $\mathrm{Fe}_{3} \mathrm{O}_{4}$ nanoparticles were carried out using a VSM. The saturation magnetic moments of pure $\mathrm{Fe}_{3} \mathrm{O}_{4}$ and $\mathrm{Fe}_{3} \mathrm{O}_{4}$ $\mathrm{SiO}_{2}$ nanoparticles were 65.5 and $31.5 \mathrm{emu} \mathrm{g}^{-1}$, respectively (Figure 5). The smallest saturation magnetization value for $\mathrm{Fe}_{3} \mathrm{O}_{4}-\mathrm{SiO}_{2}$ nanoparticles can be explained by considering the diamagnetic contribution of the silica shells surrounding the $\mathrm{Fe}_{3} \mathrm{O}_{4}$ nanoparticles [40]. In addition, both $\mathrm{Fe}_{3} \mathrm{O}_{4}$ and $\mathrm{Fe}_{3} \mathrm{O}_{4}-\mathrm{SiO}_{2}$ nanoparticles showed superparamagnetic property at room temperature. These magnetic properties are critical in the applications of MNPs in separation. An efficient magnetic separation is allowed when the MNPs undergo strong magnetization, however, when the applied magnetic field is removed, redispersion of the MNPs will take place rapidly.

\subsection{Metal Removal Experiments}

3.2.1. Chemical Affinity as a Function of $p H$. It is well documented that solution $\mathrm{pH}$ is an important parameter affecting the sorption of heavy metal ions. Therefore, the dependence of $\mathrm{Zn}$ (II) uptake on $\mathrm{pH}$ was studied at a constant $\mathrm{Zn}$ (II) concentration $\left(10 \mathrm{mg} \mathrm{L}^{-1}\right)$ using $10 \mathrm{mg}$ of the nanoadsorbent. As shown in Figure 6, $\mathrm{Zn}$ (II) adsorption increase with increasing $\mathrm{pH}$ in the range of 2.0-5.0 and is approximately independent of $\mathrm{pH}$ in the range of 5.0-8.0. Thus, $\mathrm{pH} 6.0$ was adopted for further studies. The dependence of metal sorption on $\mathrm{pH}$ is related to both the surface functional groups of the adsorbent and the metal ion chemistry in solution [41]. The hydrolysis of $\mathrm{Zn}^{2+}$ has been investigated at different $\mathrm{pHs}$ and various pressures by several authors [4246]. It has been shown that in the $\mathrm{pH}$ range 2.0-9.0 the system is quite simple, containing $\mathrm{Zn}^{2+}$ and $\mathrm{ZnOH}^{+}$ions but at higher $\mathrm{pHs} \mathrm{Zn}(\mathrm{OH})_{2}$ may precipitate [45]. Lower adsorption percentage of $\mathrm{Zn}$ (II) on the nanoparticles at highly acidic conditions $(\mathrm{pH} \leq 2)$ is probably due to the presence of high concentration of $\mathrm{H}^{+}$ions on the adsorbent surface 


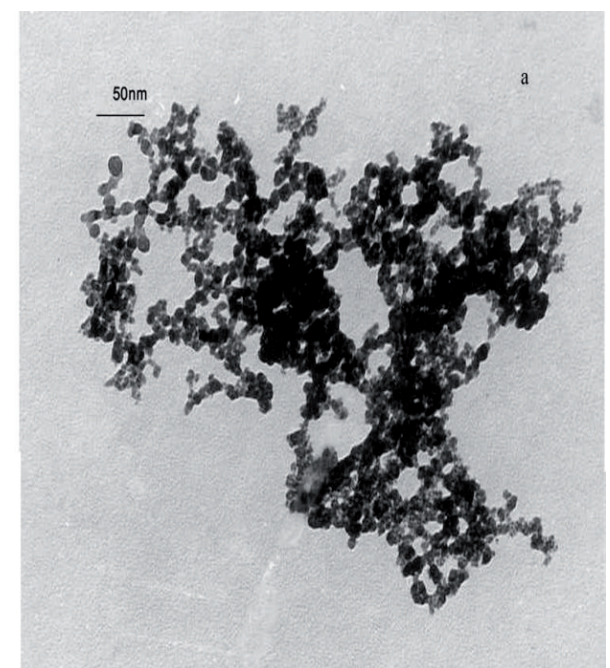

(a)

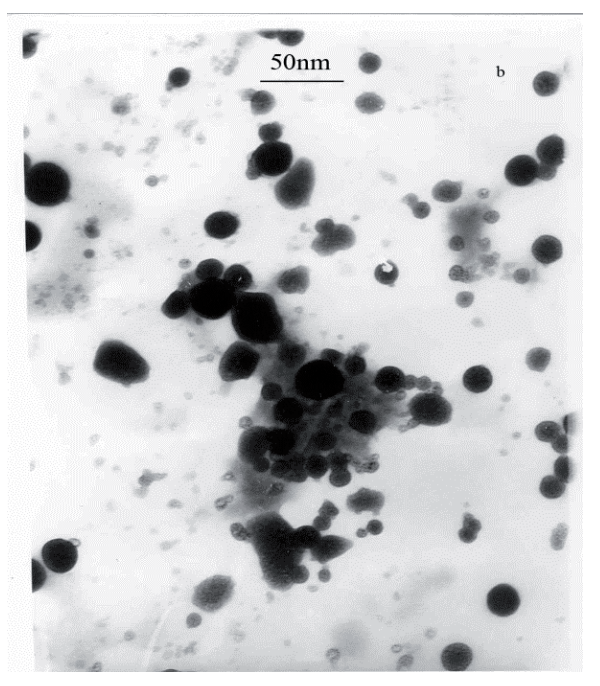

(b)

FIGURE 3: TEM images of (a) bare magnetite and (b) silica-coated magnetite.

competing with $\mathrm{Zn}$ (II) for adsorption sites. With an increase in the solution $\mathrm{pH}(3.0-8.0)$, the silanol groups become deprotonated and, consequently, the removal efficiency is increased.

\subsubsection{Effect of Contact Time and the Metal Sorption Kinetics.} One of the most important parameters that significantly describe the adsorbent characteristics is sorption time. Sorption kinetics was studied to determine the time required for the adsorption to reach the equilibrium. Figure 7 (a) shows a plot of $\mathrm{Zn}$ (II) adsorption versus contact time. The plot clearly shows three distinct regions. In the initial 5 minutes, the adsorption of $\mathrm{Zn}(\mathrm{II})$ is very rapid so that more than $90 \%$ of $\mathrm{Zn}$ (II) ions are adsorbed during this period. However, in the interval between 5 to $20 \mathrm{~min}$, the adsorption kinetics slow down and gradually tends to level off. At times greater than $20 \mathrm{~min}$ the adsorption reaches its maximum

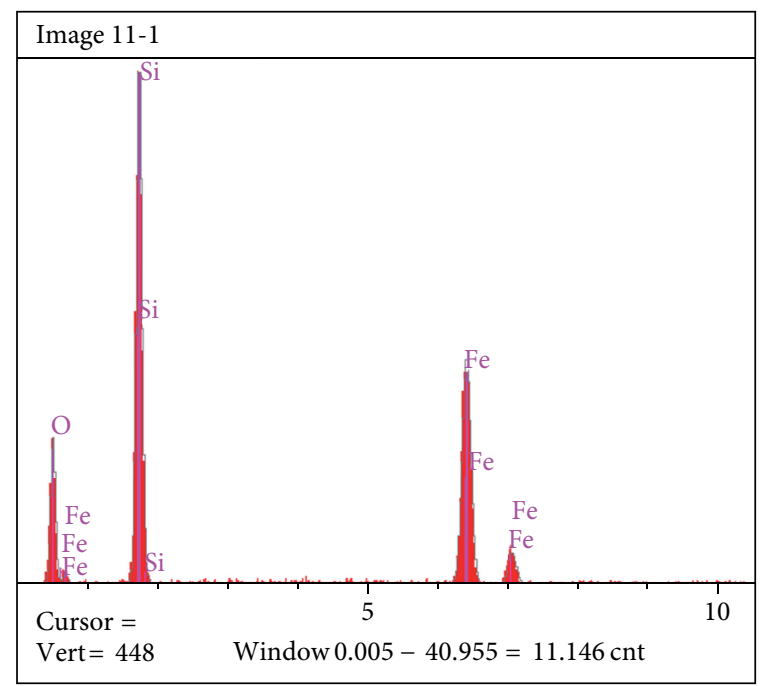

FIGURE 4: EDX spectrum of silica-coated magnetite nanoparticles.

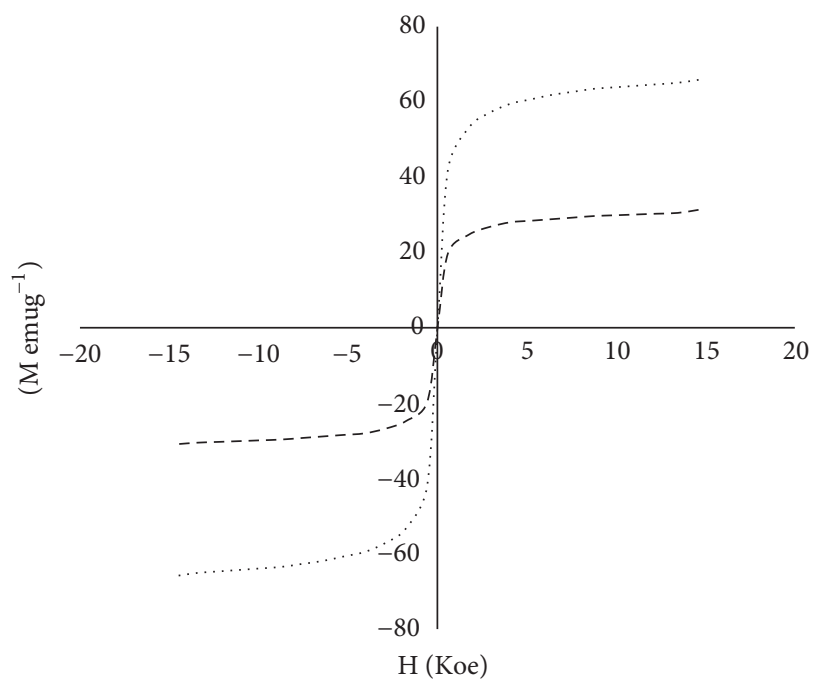

..... Magnetite
--- Magnetite-silica

FIGURE 5: VSM of (...) magnetite and (- -) silica-coated magnetite nanoparticles.

value and becomes independent of contact time, illustrating that adsorption equilibrium is achieved. The fast step of the $\mathrm{Zn}(\mathrm{II})$ adsorption may occur on the particle surface due to an immediate interaction between $\mathrm{Zn}$ (II) ions and the active $-\mathrm{SiOH}$ groups on the surface of the $\mathrm{Fe}_{3} \mathrm{O}_{4}-\mathrm{SiO}_{2}$ nanoparticles. Although the equilibrium was achieved after $20 \mathrm{~min}$, a contact time of $1 \mathrm{~h}$ was selected for further works to be confident of the equilibrium establishment.

The pseudo-first-order and pseudo-second-order kinetic equations were chosen to fit the obtained adsorption kinetics data and to estimate the rate constant of the adsorption phenomenon. 


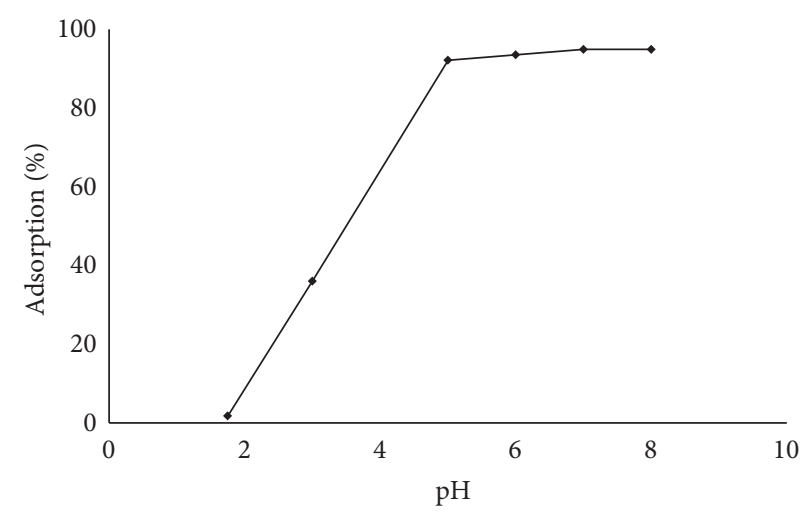

FIGURE 6: Effect of solution $\mathrm{pH}$ on the adsorption of $\mathrm{Zn}(\mathrm{II})$ onto $\mathrm{Fe}_{3} \mathrm{O}_{4}-\mathrm{SiO}_{2}$ nanoparticles adsorbent. Conditions: $10.0 \mathrm{~mL}$ of $10.0 \mathrm{mg} \mathrm{L}^{-1}$ $\mathrm{Zn}$ (II) solution and $10.0 \mathrm{mg}$ of adsorbent.

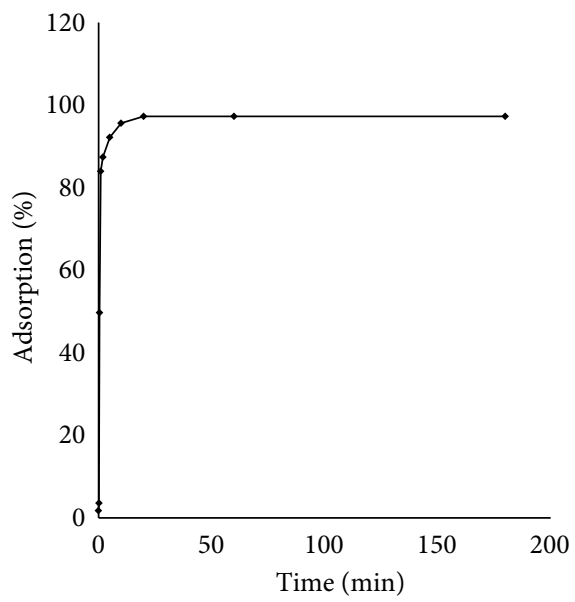

(a)

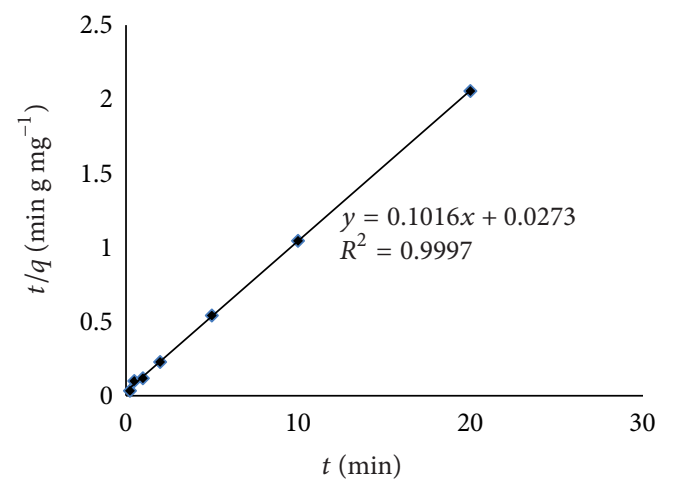

(b)

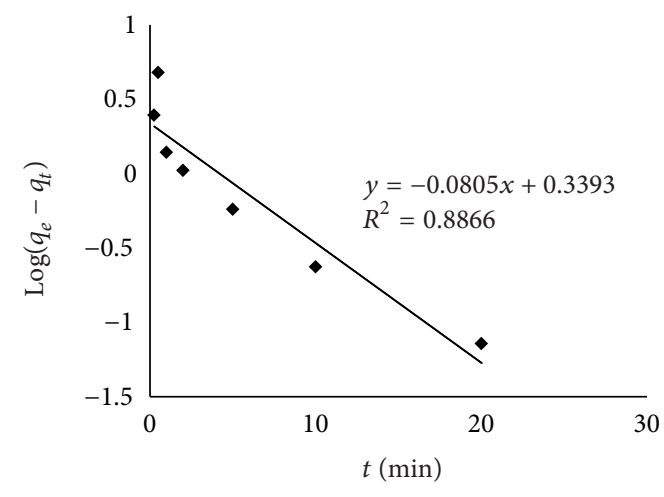

(c)

FIGURE 7: Effect of contact time on the adsorption of $\mathrm{Zn}$ (II) onto the $\mathrm{Fe}_{3} \mathrm{O}_{4}-\mathrm{SiO}_{2}$ nanoparticles at room temperature and $\mathrm{pH} 6.0$ (a), and the corresponding plots of pseudo-first-order (b) and pseudo-second-order (c) kinetic models. Conditions are the same as Figure 5.

The pseudo-first-order rate equation is generally expressed as:

$$
\log \left(q_{e}-q_{t}\right)=\log q_{e}-\frac{k_{1} t}{2.303}
$$

where $q_{e}$ and $q_{t}$ are the amount of species adsorbed per unit mass of adsorbent $\left(\mathrm{mg} \mathrm{g}^{-1}\right)$ at equilibrium and any time $t$, respectively and $k_{1}$ is the rate constant of pseudo-first-order adsorption $\left(\mathrm{min}^{-1}\right)$.

The pseudo-second-order rate equation is given as follows:

$$
\frac{t}{q_{t}}=\frac{1}{k_{2} q_{e}^{2}}+\frac{t}{q_{e}}
$$




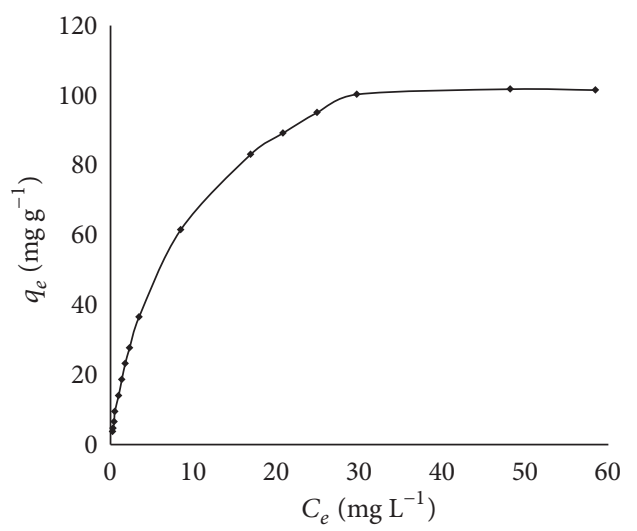

(a)

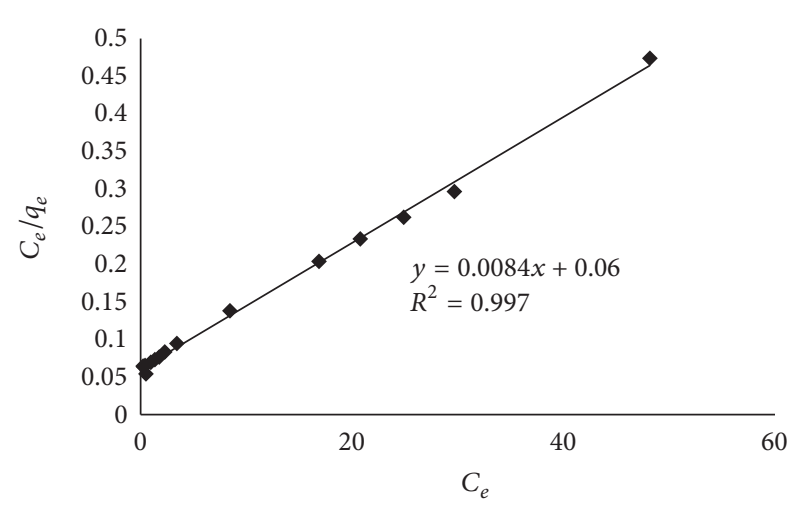

(b)

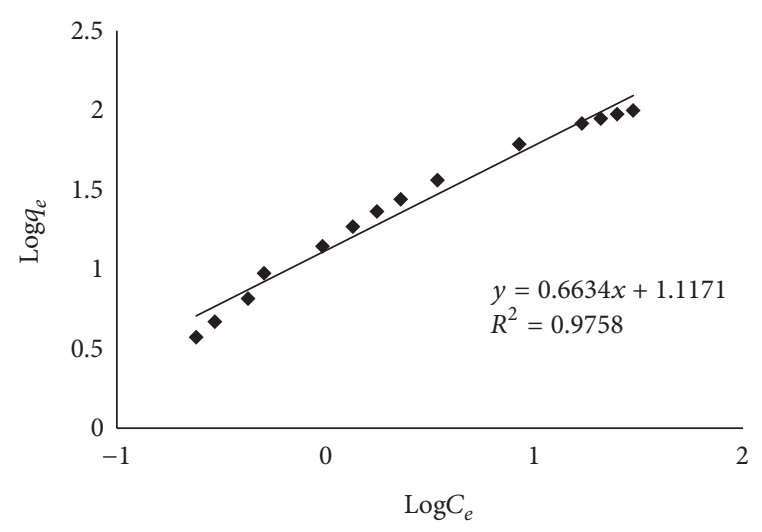

(c)

FIgURE 8: Adsorption of $\mathrm{Zn}(\mathrm{II})$ ions the $\mathrm{Fe}_{3} \mathrm{O}_{4}-\mathrm{SiO}_{2}$ nanoparticles at $\mathrm{pH} 6.0$ and room temperature as a function of initial $\mathrm{Zn}$ (II) concentration (a), and the corresponding Langmuir (b) and Freundlich (c) isotherm plots.

where $k_{2}$ is the rate constant of pseudo-second-order sorption $\left(\mathrm{g} \mathrm{mg}^{-1} \mathrm{~min}^{-1}\right)$.

Figures 7(b) and 6(c) show the results of this study, presented as plots of $\log \left(q_{e}-q_{t}\right)$ and $t / q_{t}$ versus $t$ from zero to 20 minutes. As shown in these figures, the adsorption of $\mathrm{Zn}$ (II) onto $\mathrm{Fe}_{3} \mathrm{O}_{4}-\mathrm{SiO}_{2}$ nanoparticles is more appropriately described by a pseudo-second-order kinetic model since its correlation coefficient (0.999) is greater than that of the pseudofirst-order model (0.886) and also the difference between the theoretical $q_{e}\left(10 \mathrm{mgg}^{-1}\right)$ and experimental $q_{e}\left(9.9 \mathrm{mg} \mathrm{g}^{-1}\right)$ is smaller than the values calculated based on the pseudofirst-order kinetic model $\left(3 \mathrm{mg} \mathrm{g}^{-1}\right)$. The rate constant of the pseudo-second-order adsorption of $\mathrm{Zn}$ (II) onto $\mathrm{Fe}_{3} \mathrm{O}_{4}-\mathrm{SiO}_{2}$ nanoparticles, $k_{2}$, was found to be $0.37 \mathrm{~g} \mathrm{mg}^{-1} \mathrm{~min}^{-1}$.

\subsubsection{Effect of Initial Zn(II) Concentration and Metal Sorption} Isotherms. To find maximum capacity of the adsorbent which is very important for the design of adsorption systems, the equilibrium adsorption isotherms were constructed. The adsorption isotherm of $\mathrm{Zn}$ (II) ions by the MNPs at constant pH 6.0 is shown in Figure 8(a). Based on the kinetic studies, a period of $1 \mathrm{~h}$ was selected as the contact time to ensure that equilibrium is reached. The equilibrium data were analyzed according to the linear form of the Langmuir sorption isotherm as:

$$
\frac{c_{e}}{q_{e}}=\frac{1}{K_{L} q_{\max }}+\frac{1}{q_{\max }} c_{e},
$$

where $q_{e}$ is the adsorption capacity $\left(\mathrm{mgg}^{-1}\right)$ based on the dry weight of nanoadsorbent, $C_{e}$ is the equilibrium concentration of metal ion $\left(\mathrm{mg} \mathrm{L}^{-1}\right)$ in solution, $q_{\max }$ is the maximum adsorption capacity $\left(\mathrm{mg} \mathrm{g}^{-1}\right)$ of metal that can be adsorbed in a monolayer, and $K_{L}$ is the Langmuir adsorption equilibrium constant $\left(\mathrm{L} \mathrm{mg}^{-1}\right)$ that is related to the energy of adsorption. The Langmuir plot is represented in Figure 8(b). The parameters of this model, calculated from Figure 8(b), are given in Table 1. A good agreement between the model and the experimental data suggests that the sorbed $\mathrm{Zn}$ (II) ions form a monolayer on the adsorbent surface.

The Freundlich model, which assumes that different sites with several adsorption energies are involved, was also tested to describe the sorption data. The linear representation of the Freundlich adsorption equation is

$$
\log q_{e}=\log K_{F}+\frac{1}{n} \log C_{e},
$$


TABLE 1: Isotherm models for $\mathrm{Zn}(\mathrm{II})$ sorption onto magnetic nanoparticles.

\begin{tabular}{lcccc}
\hline Mathematical model & Equation & Correlation coefficient & $q_{m}\left(\mathrm{mgg}^{-1}\right)$ or $1 / n$ & $K_{L}\left(\mathrm{~L} \mathrm{mg}^{-1}\right) \mathrm{or} \mathrm{K}_{F}\left(\mathrm{~L} \mathrm{mg}^{-1}\right)$ \\
\hline Langmuir & $c_{e} / q_{e}=0.059+0.008 c_{e}$ & 0.997 & 125.0 & 0.1356 \\
Freundlich & $\log q_{\mathrm{e}}=1.117+0.663 \log c_{\mathrm{e}}$ & 0.975 & 0.663 & 13.09 \\
\hline
\end{tabular}

TABLE 2: Important parameters of several adsorption systems for removal of $\mathrm{Zn}$ (II) from aqueous solutions.

\begin{tabular}{|c|c|c|c|c|}
\hline Adsorbent & $\begin{array}{l}\text { Maximum adsorption capacity } \\
\left(\mathrm{mg} \mathrm{g}^{-1}\right)\end{array}$ & $\begin{array}{l}\text { Equilibrium time } \\
(\min )\end{array}$ & Reusability & Reference \\
\hline $\begin{array}{l}\text { Alternanthera philoxeroides } \\
\text { biomass }\end{array}$ & 18.57 & 60 & Not reported & {$[39]$} \\
\hline Native Lentinus edodes pellets & 37.7 & \multirow[t]{2}{*}{120} & \multirow[t]{2}{*}{ Not reported } & \multirow[t]{2}{*}[45]{} \\
\hline Inactive Lentinus edodes pellets & 63.3 & & & \\
\hline Lewatit MonoPlus M 600 & 80.64 & \multirow{4}{*}{20} & \multirow{4}{*}{$\begin{array}{l}\text { Retained about } 95 \% \text { of its } \\
\text { initial efficiency after } 10 \text { cycles }\end{array}$} & \multirow{4}{*}[9]{} \\
\hline Lewatit MonoPlus MP 500 & 18.01 & & & \\
\hline Lewatit MonoPlus MP 64 & 24.44 & & & \\
\hline Amberlite IRA 402 & 31.94 & & & \\
\hline $\begin{array}{l}\text { Hybrid precursor of silicon and } \\
\text { carbon }\end{array}$ & 28.76 & 30 & Not reported & {$[46]$} \\
\hline $\begin{array}{l}\text { Sulfuric acid-treated rice husk (dry } \\
\text { sorbent) }\end{array}$ & 18.94 & \multirow{2}{*}{120} & \multirow{2}{*}{ Not reported } & \multirow{2}{*}[47]{} \\
\hline $\begin{array}{l}\text { Sulfuric acid-treated rice husk (wet } \\
\text { sorbent) }\end{array}$ & 19.38 & & & \\
\hline Lemon peel & 27.86 & \multirow{3}{*}{600} & \multirow{3}{*}{ Not reported } & \multirow{3}{*}[48]{} \\
\hline Lemon peel cellulose (LPC) & 112.36 & & & \\
\hline Surface-modified LPC (LPCACS) & 222.22 & & & \\
\hline $\begin{array}{l}\text { Amidoximated } \\
\text { polyacrylonitrile/organobentonite } \\
\text { composite }\end{array}$ & 65.40 & $90-180$ & $\begin{array}{l}\text { Retained about } 85 \% \text { of its } \\
\text { initial efficiency after } 4 \text { cycles }\end{array}$ & [49] \\
\hline $\begin{array}{l}\text { Magnetic hydroxyapatite } \\
\text { nanoparticles }\end{array}$ & 140.6 & 576 & $\begin{array}{c}\text { Desorption efficiency in first } \\
\text { cycle } 67 \%\end{array}$ & {$[50]$} \\
\hline $\begin{array}{l}\text { Magnetic nanoparticles coated with } \\
\text { silica }\end{array}$ & 119 & 20 & $\begin{array}{l}\text { Retained about } 93 \% \text { of its } \\
\text { initial efficiency after } 7 \text { cycles }\end{array}$ & This work \\
\hline
\end{tabular}

where $K_{F}$ is the energy term and $n$ is an exponent term related to the strength of the adsorption. The Freundlich plot is shown in Figure $8(c)$ and the $K_{F}$ and $1 / n$ parameters with the corresponding determination coefficient, $R^{2}$, are presented in Table 1.

Table 1 shows that the adsorption behavior of $\mathrm{Zn}(\mathrm{II})$ ions onto the magnetic nanoparticles is best described by the Langmuir isotherm model because this model yields a higher determination coefficient and a smaller difference between theoretical $q_{\max }\left(119 \mathrm{mg} \mathrm{g}^{-1}\right)$ and experimental $q_{e}$ $\left(101 \mathrm{mgg}^{-1}\right)$.

3.2.4. Desorption and Reusability Studies. Restoring the adsorption capacity of exhausted adsorbents is an important factor in practical application. Therefore, the reusability of the $\mathrm{Fe}_{3} \mathrm{O}_{4}-\mathrm{SiO}_{2}$ was tested. To investigate the possibility of restoring the adsorption capacity, at first desorption experiments were conducted under batch experimental conditions. The suppressed adsorption of $\mathrm{Zn}(\mathrm{II})$ ions on $\mathrm{Fe}_{3} \mathrm{O}_{4}-\mathrm{SiO}_{2}$ nanoparticles at low pHs (Figure 6) implies that the adsorbent could be regenerated by acid treatment. Among the various examined acids including acetic acid, hydrochloric acid, sulfuric acid and nitric acid (all at $0.1 \mathrm{M}$ concentration), hydrochloric acid showed the best regenerating results. The effect of $\mathrm{HCl}$ concentration on the regeneration efficiency was also studied and it was observed that the desorption efficiency increases with increasing the acid concentration up to $1.0 \mathrm{M}$ and then remained constant. Therefore, $1.0 \mathrm{M}$ hydrochloric acid was used as the optimum for all subsequent experiments. The stability of $\mathrm{Fe}_{3} \mathrm{O}_{4}-\mathrm{SiO}_{2}$ nanoparticles under acidic conditions was also examined by measuring the extent of Fe leached into the solution per gram of the adsorbent after contacting it for $12 \mathrm{~h}$ with $1.0 \mathrm{M}$ hydrochloric acid. The Fe leaching of less than 3 wt.\% confirmed the stability of the adsorbent under acidic conditions, which be related to the effect of silica coating.

The reusability of the adsorbent for zinc ion adsorption was tested by repeating the adsorption-desorption cycle several times using the same adsorbent. The result of this study showed that the adsorbent retained about $93 \%$ of its initial sorption efficiency after 7 cycles. This property allows multiple uses of adsorbents for at least 7 times. 


\section{Conclusions}

The present study demonstrates that $\mathrm{Fe}_{3} \mathrm{O}_{4}-\mathrm{SiO}_{2}$ nanoparticles are promising adsorbents for efficient removal of $\mathrm{Zn}$ (II) from aqueous solutions (see Table 2). The efficiency of adsorption was highly dependent on the initial concentration of $\mathrm{Zn}(\mathrm{II}), \mathrm{pH}$, adsorbent dosage, and contact time. Langmuir and Freundlich isotherm models were employed to describe the $\mathrm{Zn}$ (II) adsorption. It was found that the adsorption behavior of $\mathrm{Zn}(\mathrm{II})$ ions onto the MNPs is best described by the Langmuir isotherm model. Zn(II) showed fast sorption kinetics following pseudo-second-order model. The equilibrium for $\mathrm{Zn}$ (II) adsorption onto the $\mathrm{Fe}_{3} \mathrm{O}_{4}-\mathrm{SiO}_{2}$ nanoparticles reached only after 20 minutes. The adsorbent can be easily and effectively regenerated by using $1.0 \mathrm{M} \mathrm{HCl}$ as the regenerating solution. Further, due to protection by inert silica layer, leaching of $\mathrm{Fe}_{3} \mathrm{O}_{4}$ during the adsorption and regeneration processes is negligible, hence the adsorbent can be used for multiple sorption-desorption steps. The adsorbent could be easily separated from the sorbing and regeneration solutions in short times $(1.0 \mathrm{~min})$ by using a magnet. The proposed adsorbent offers attractive properties compared to the previous ones such as high adsorption capacity $\left(119 \mathrm{mg} \mathrm{g}^{-1}\right)$, short equilibration $(20 \mathrm{~min})$ and sedimentation (1 $\mathrm{min})$ times, and high stability. In conclusion, the above system can be a potential candidate for the practical removal of $\mathrm{Zn}$ (II) from aqueous solutions.

\section{Acknowledgments}

Financial support for this work by University of Isfahan is gratefully acknowledged. The authors have declared no conflict of interests.

\section{References}

[1] Z. Reddad, C. Gerente, Y. Andres, and P. Le Cloirec, "Adsorption of several metal ions onto a low-cost biosorbent: kinetic and equilibrium studies," Environmental Science and Technology, vol. 36, no. 9, pp. 2067-2073, 2002.

[2] H. J. Fan, H. Y. Shu, H. S. Yang, and W. C. Chen, "Characteristics of landfill leachates in central Taiwan," Science of the Total Environment, vol. 361, no. 1-3, pp. 25-37, 2006.

[3] A. K. Bhattacharya, S. N. Mandal, and S. K. Das, "Adsorption of $\mathrm{Zn}$ (II) from aqueous solution by using different adsorbents," Chemical Engineering Journal, vol. 123, no. 1-2, pp. 43-51, 2006.

[4] A. S. Luna, A. L. H. Costa, A. C. A. da Costa, and C. A. Henriques, "Competitive biosorption of cadmium(II) and zinc(II) ions from binary systems by Sargassum filipendula," Bioresource Technology, vol. 101, no. 14, pp. 5104-5111, 2010.

[5] E. L. Cochrane, S. Lu, S. W. Gibb, and I. Villaescusa, "A comparison of low-cost biosorbents and commercial sorbents for the removal of copper from aqueous media, Journal of Hazardous Materials, vol. 137, no. 1, pp. 198-206, 2006.

[6] I. C. Kantarli and J. Yanik, "Activated carbon from leather shaving wastes and its application in removal of toxic materials," Journal of Hazardous Materials, vol. 179, no. 1-3, pp. 348-356, 2010.

[7] S. Çoruh, G. Şenel, and O. N. Ergun, "A comparison of the properties of natural clinoptilolites and their ion-exchange capacities for silver removal," Journal of Hazardous Materials, vol. 180, no. 1-3, pp. 486-492, 2010.

[8] M. K. Doula, "Simultaneous removal of $\mathrm{Cu}, \mathrm{Mn}$ and $\mathrm{Zn}$ from drinking water with the use of clinoptilolite and its Fe-modified form," Water Research, vol. 43, no. 15, pp. 3659-3672, 2009.

[9] D. Kolodyńska, Z. Hubicki, and A. Skiba, "Heavy metal ions removal in the presence of 1-hydroxyethane-1,1- diphosphonic acid from aqueous solutions on polystyrene anion exchangers," Industrial and Engineering Chemistry Research, vol. 48, no. 23, pp. 10584-10593, 2009.

[10] M. E. Mahmoud, I. M. M. Kenawy, M. A. H. Hafez, and R. R. Lashein, "Removal, preconcentration and determination of trace heavy metal ions in water samples by AAS via chemically modified silica gel N-(1-carboxy-6-hydroxy) benzylidenepropylamine ion exchanger," Desalination, vol. 250, no. 1, pp. 62-70, 2010.

[11] Y. L. Lai, G. Annadurai, F. C. Huang, and J. F. Lee, "Biosorption of $\mathrm{Zn}(\mathrm{II})$ on the different Ca-alginate beads from aqueous solution," Bioresource Technology, vol. 99, no. 14, pp. 6480-6487, 2008.

[12] O. Ozay, S. Ekici, Y. Baran, N. Aktas, and N. Sahiner, "Removal of toxic metal ions with magnetic hydrogels," Water Research, vol. 43, no. 17, pp. 4403-4411, 2009.

[13] R. K. Sharma and Lalita, "Synthesis and characterization of graft copolymers of N-Vinyl-2-Pyrrolidone onto guar gum for sorption of $\mathrm{Fe}^{2+}$ and $\mathrm{Cr}^{6+}$ ions," Carbohydrate Polymers, vol. 83, no. 4, pp. 1929-1936, 2011.

[14] Y. T. Zhou, H. L. Nie, C. Branford-White, Z. Y. He, and L. $\mathrm{M}$. Zhu, "Removal of $\mathrm{Cu}^{2+}$ from aqueous solution by chitosancoated magnetic nanoparticles modified with $\alpha$-ketoglutaric acid," Journal of Colloid and Interface Science, vol. 330, no. 1, pp. 29-37, 2009.

[15] O. M. Kalfa, Z. Yalçinkaya, and A. R. Türker, "Synthesis of nano $\mathrm{B}_{2} \mathrm{O}_{3} / \mathrm{TiO}_{2}$ composite material as a new solid phase extractor and its application to preconcentration and separation of cadmium," Journal of Hazardous Materials, vol. 166, no. 1, pp. 455-461, 2009.

[16] Q. Zhang, B. Pan, B. Pan, W. Zhang, K. Jia, and Q. Zhang, "Selective sorption of lead, cadmium and zinc ions by a polymeric cation exchanger containing nano- $\mathrm{Zr}\left(\mathrm{HPO}_{3} \mathrm{~S}\right)_{2}$," Environmental Science and Technology, vol. 42, no. 11, pp. 4140-4145, 2008.

[17] Y. Liu, P. Liang, and L. Guo, "Nanometer titanium dioxide immobilized on silica gel as sorbent for preconcentration of metal ions prior to their determination by inductively coupled plasma atomic emission spectrometry," Talanta, vol. 68, no. 1, pp. 25-30, 2005.

[18] X. Liu, Q. Hu, Z. Fang, X. Zhang, and B. Zhang, "Magnetic chitosan nanocomposites: a useful recyclable tool for heavy metal ion removal," Langmuir, vol. 25, no. 1, pp. 3-8, 2009.

[19] W. Yantasee, C. L. Warner, T. Sangvanich et al., "Removal of heavy metals from aqueous systems with thiol functionalized superparamagnetic nanoparticles," Environmental Science and Technology, vol. 41, no. 14, pp. 5114-5119, 2007.

[20] A.-F. Ngomsik, A. Bee, J.-M. Siaugue, V. Cabuil, and G. Cote, "Nickel adsorption by magnetic alginate microcapsules containing an extractant," Water Research, vol. 40, no. 9, pp. 1848-1856, 2006.

[21] H. Li, Z. Li, T. Liu, X. Xiao, Z. Peng, and L. Deng, "A novel technology for biosorption and recovery hexavalent chromium in wastewater by bio-functional magnetic beads," Bioresource Technology, vol. 99, no. 14, pp. 6271-6279, 2008. 
[22] J. Hu, G. Chen, and I. M. C. Lo, "Removal and recovery of $\mathrm{Cr}(\mathrm{VI})$ from wastewater by maghemite nanoparticles," Water Research, vol. 39, no. 18, pp. 4528-4536, 2005.

[23] Y. Ren, X. Wei, and M. Zhang, "Adsorption character for removal $\mathrm{Cu}$ (II) by magnetic $\mathrm{Cu}$ (II) ion imprinted composite adsorbent," Journal of Hazardous Materials, vol. 158, no. 1, pp. 14-22, 2008.

[24] C. T. Yavuz, W. W. Yu, A. Prakash et al., "Low-field magnetic separation of monodisperse $\mathrm{Fe}_{3} \mathrm{O}_{4}$ nanocrystals," Science, vol. 314, no. 5801, pp. 964-967, 2006.

[25] B. Hai, J. Wu, X. Chen, J. D. Protasiewicz, and D. A. Scherson, "Metal-ion adsorption on carboxyl-bearing self-assembled monolayers covalently bound to magnetic nanoparticles," Langmuir, vol. 21, no. 7, pp. 3104-3105, 2005.

[26] Y. C. Chang and D. H. Chen, "Preparation and adsorption properties of monodisperse chitosan-bound $\mathrm{Fe}_{3} \mathrm{O}_{4}$ magnetic nanoparticles for removal of $\mathrm{Cu}(\mathrm{II})$ ions," Journal of Colloid and Interface Science, vol. 283, no. 2, pp. 446-451, 2005.

[27] J. F. Liu, Z. S. Zhao, and G.-B. Jiang, "Coating $\mathrm{Fe}_{3} \mathrm{O}_{4}$ magnetic nanoparticles with humic acid for high efficient removal of heavy metals in water," Environmental Science and Technology, vol. 42, no. 18, pp. 6949-6954, 2008.

[28] Y.-T. Zhou, C. Branford-White, H.-L. Nie, and L.-M. Zhu, "Adsorption mechanism of $\mathrm{Cu}^{2+}$ from aqueous solution by chitosan-coated magnetic nanoparticles modified with $\alpha$ ketoglutaric acid," Colloids and Surfaces B, vol. 74, no. 1, pp. 244-252, 2009.

[29] M. Mahmoudi, S. Sant, B. Wang, S. Laurent, and T. Sen, "Superparamagnetic iron oxide nanoparticles (SPIONs): development, surface modification and applications in chemotherapy," Advanced Drug Delivery Reviews, vol. 63, no. 1-2, pp. 24-46, 2011.

[30] R. T. Yang, Adsorbents: Fundamentals and Applications, John Wiley \& Sons, 2003.

[31] R. K. Iller, The Chemistry of Silica, John Wiley \& Sons, 1979.

[32] J. Wang, S. Zheng, Y. Shao, J. Liu, Z. Xu, and D. Zhu, "Aminofunctionalized $\mathrm{Fe}_{3} \mathrm{O}_{4} @ \mathrm{SiO}_{2}$ core-shell magnetic nanomaterial as a novel adsorbent for aqueous heavy metals removal," Journal of Colloid and Interface Science, vol. 349, no. 1, pp. 293-299, 2010.

[33] C. Huang and B. Hu, "Silica-coated magnetic nanoparticles modified with $\gamma$-mercaptopropyltrimethoxysilane for fast and selective solid phase extraction of trace amounts of $\mathrm{Cd}, \mathrm{Cu}, \mathrm{Hg}$, and $\mathrm{Pb}$ in environmental and biological samples prior to their determination by inductively coupled plasma mass spectrometry," Spectrochimica Acta B, vol. 63, no. 3, pp. 437-444, 2008.

[34] P. Yin, Q. Xu, R. Qu, and G. Zhao, "Removal of transition metal ions from aqueous solutions by adsorption onto a novel silica gel matrix composite adsorbent," Journal of Hazardous Materials, vol. 169, no. 1-3, pp. 228-232, 2009.

[35] H. Yang, R. Xu, X. Xue, F. Li, and G. Li, "Hybrid surfactanttemplated mesoporous silica formed in ethanol and its application for heavy metal removal," Journal of Hazardous Materials, vol. 152, no. 2, pp. 690-698, 2008.

[36] D. Yang, J. Hu, and S. Fu, "Controlled synthesis of Magnetite-Silica nanocomposites via a seeded sol-gel approach," The Journal of Physical Chemistry C, vol. 113, no. 18, pp. 7646-7651, 2009.

[37] R. Massart, "Preparation of aqueous magnetic liquids in alkaline and acidic media," IEEE Transactions on Magnetics, vol. 17, no. 2, pp. 1247-1248, 1981.
[38] W. F. Stöber, A. Fink, and E. Bohn, "Controlled growth of monodisperse silica spheres in the micron size range," Journal of Colloid and Interface Science, vol. 26, no. 1, pp. 62-69, 1968.

[39] D. M. Souza, A. L. Andrade, J. D. Fabris et al., "Synthesis and in vitro evaluation of toxicity of silica-coated magnetite nanoparticles," Journal of Non-Crystalline Solids, vol. 354, no. 42-44, pp. 4894-4897, 2008.

[40] A.-L. Morel, S. I. Nikitenko, K. Gionnet et al., "Sonochemical approach to the synthesis of $\mathrm{Fe}_{3} \mathrm{O}_{4} @ \mathrm{SiO}_{2}$ core-shell nanoparticles with tunable properties," ACS Nano, vol. 2, no. 5, pp. 847-856, 2008.

[41] X.-S. Wang and Y. Qin, "Removal of Ni(II), Zn(II) and Cr(VI) from aqueous solution by Alternanthera philoxeroides biomass," Journal of Hazardous Materials, vol. 138, no. 3, pp. 582-588, 2006.

[42] D. H. Y. Hanzawa, C. Matsuura, K. Ishigure, M. Nagao, and M. Haginuma, "Hydrolysis of zinc ion and solubility of zinc oxide in high-temperature aqueous systems," Nuclear Science and Engineering, vol. 127, no. 3, pp. 292-299, 1997.

[43] P. Bénézeth, D. A. Palmer, and D. J. Wesolowski, "The solubility of zinc oxide in $0.03 \mathrm{~m} \mathrm{NaTr}$ as a function of temperature, with in situ $\mathrm{pH}$ measurement," Geochimica et Cosmochimica Acta, vol. 63, no. 10, pp. 1571-1586, 1999.

[44] P. P. Bénézeth, D. A. Palmer, D. J. Wesolowski, and C. Xiao, "New measurements of the solubility of zinc oxide from 150 to $350^{\circ} \mathrm{C}$," Journal of Solution Chemistry, vol. 31, no. 12, pp. 947-973, 2002.

[45] T. N. T. Phan, N. Louvard, S. A. Bachiri, J. Persello, and A. Foissy, "Adsorption of zinc on colloidal silica, triple layer modelization and aggregation data," Colloids and Surfaces A, vol. 244, no. 1-3, pp. 131-140, 2004.

[46] A. Farajtabar, F. Gharib, P. Jamaat, and N. Safari, "Complexation of 5,10,15,20-tetrakis(4-sulfonatophenyl)porphyrin with zinc(II) ions in aqueous solution," Journal of Chemical and Engineering Data, vol. 53, no. 2, pp. 350-354, 2008.

[47] G. Bayramo囚lu and M. Y. Arica, "Removal of heavy mercury(II), cadmium(II) and zinc(II) metal ions by live and heat inactivated Lentinus edodes pellets," Chemical Engineering Journal, vol. 143, no. 1-3, pp. 133-140, 2008.

[48] N. Gupta, S. Amritphale, and N. Chandra, "Removal of Zn (II) from aqueous solution by using hybrid precursor of silicon and carbon," Bioresource Technology, vol. 101, no. 10, pp. 3355-3362, 2010.

[49] E. El-Shafey, "Removal of $\mathrm{Zn}(\mathrm{II})$ and $\mathrm{Hg}$ (II) from aqueous solution on a carbonaceous sorbent chemically prepared from rice husk," Journal of Hazardous Materials, vol. 175, no. 1-3, pp. 319-327, 2010.

[50] M. Thirumavalavan, Y. L. Lai, L. C. Lin, and J. F. Lee, "Cellulosebased native and surface modified fruit peels for the adsorption of heavy metal ions from aqueous solution: langmuir adsorption isotherms," Journal of Chemical and Engineering Data, vol. 55, no. 3, pp. 1186-1192, 2010. 

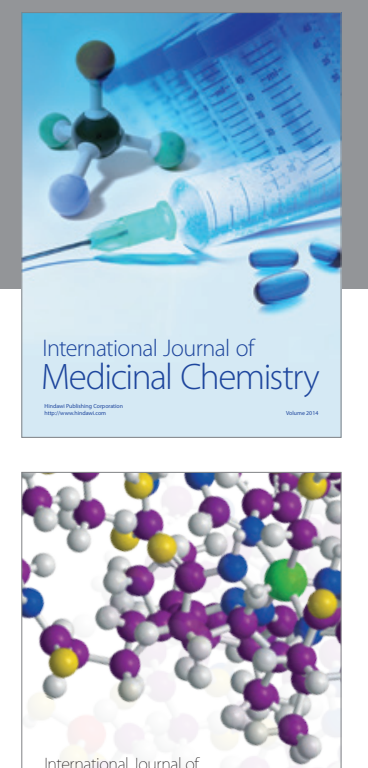

\section{Carbohydrate} Chemistry

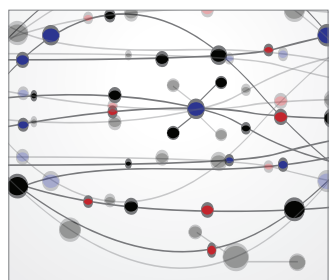

The Scientific World Journal
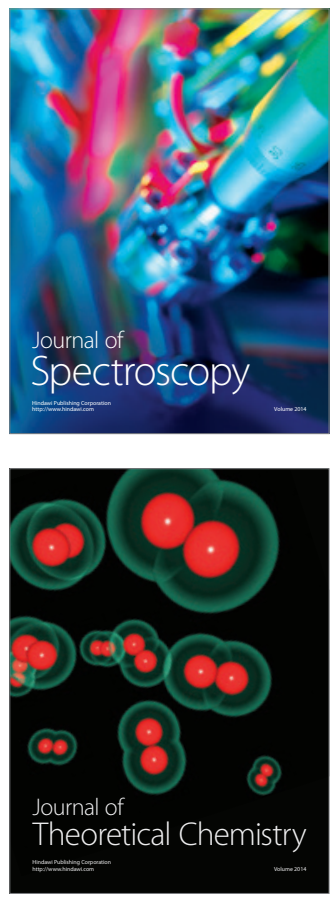
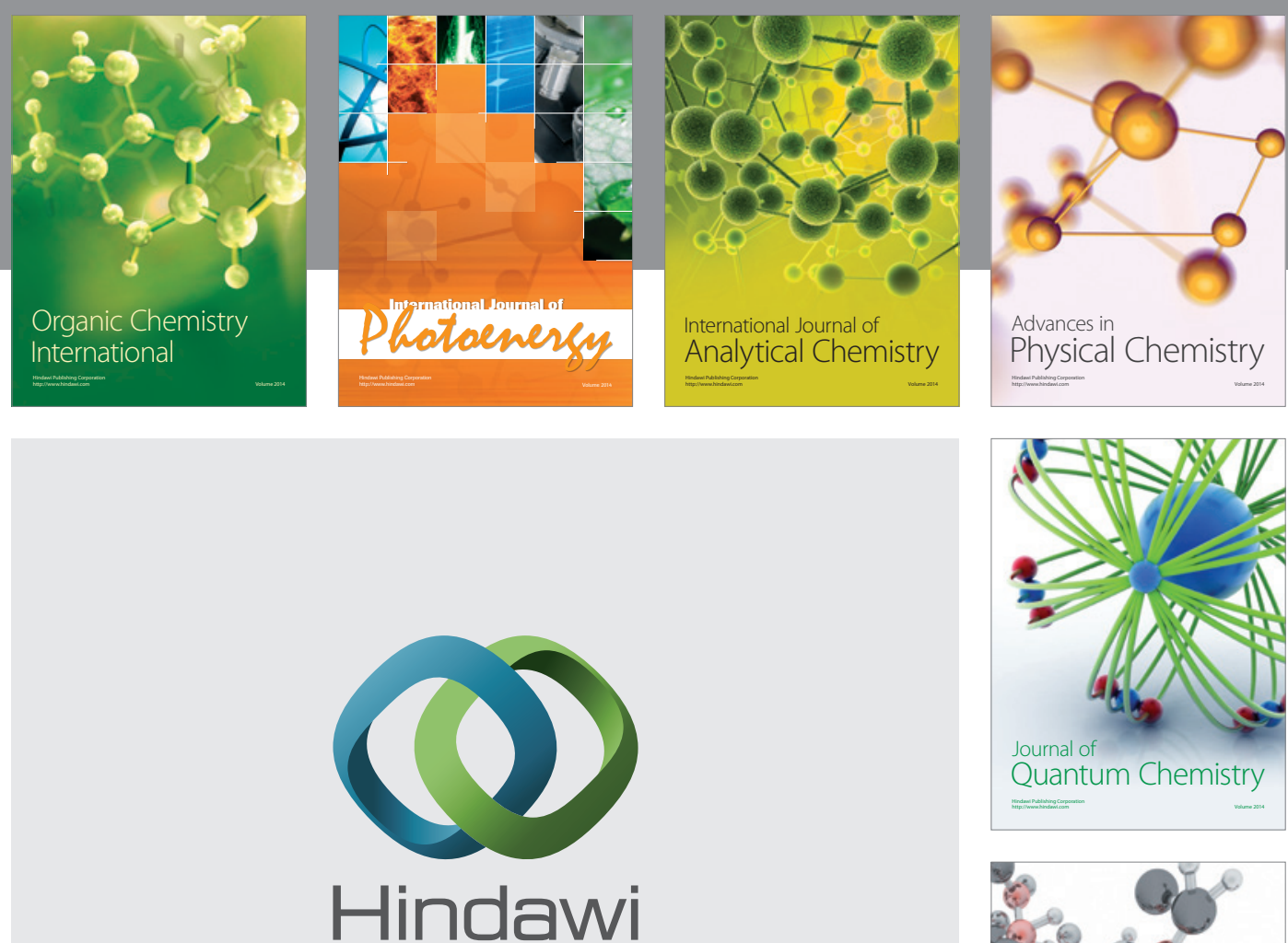

Submit your manuscripts at

http://www.hindawi.com

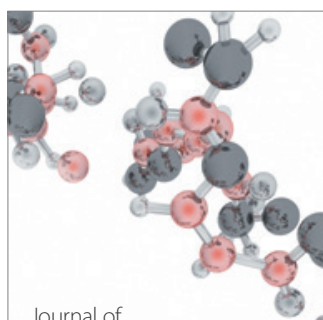

Analytical Methods

in Chemistry

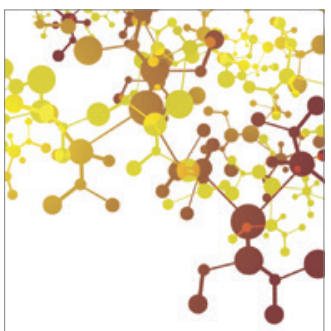

Journal of

Applied Chemistry

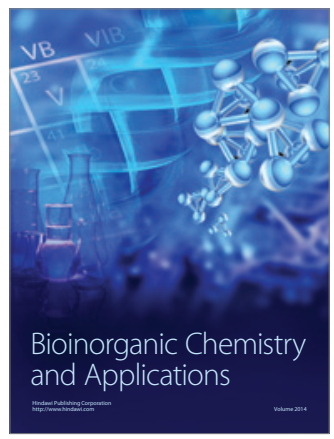

Inorganic Chemistry
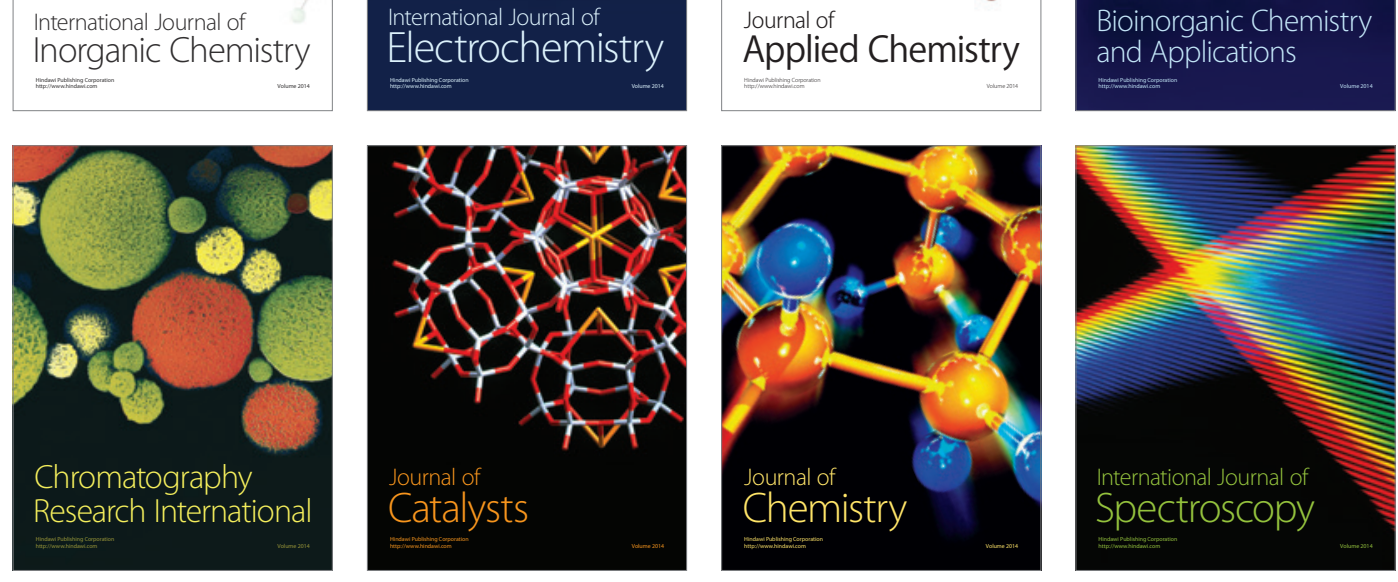